\title{
Techno-Economic Analysis of HVAC, HVDC and OFAC Offshore Wind Power Connections.
}

\author{
S. Hardy, K. Van Brusselen, S. Hendrix \\ CG Holdings Belgium NV - Systems Division \\ Mechelen, Belgium
}

\author{
Prof. D. Van Hertem, Dr H. Ergun \\ KU Leuven, Dept. Electr. Eng (ESAT) \\ Heverlee, Belgium
}

\begin{abstract}
This work performs an economic analysis of HVAC and HVDC transmission options for Offshore Wind Power Plants (OWPPs). The primary objective is to produce a range for each technology under which it is the most economic option. The economic model developed accounts for system losses and reliability. HVAC technological variations included are the use of a mid point compensation platform and Optimal Frequency AC (OFAC). The investigation found mid point compensation to be highly beneficial, significantly increasing the economic range of HVAC via smaller cable sizes and reduced Expected Energy Not Served (EENS). An opportunity for optimal offshore grid expansion requiring limited up front investment using mid point compensation is presented. The viable range of OFAC was found to be limited. Furthermore, a reduction in export cable size was found to frequently be economic and the use of 2 transformers over 1 for improved reliability; warranted.
\end{abstract}

Index Terms-Cost benefit analysis, offshore power plants, transmission systems, wind energy.

\section{INTRODUCTION}

In 2017, $3148 \mathrm{MW}$ of new offshore wind capacity was added to the European grid. The average OWPP added was $493 \mathrm{MW}$ at a distance of $41 \mathrm{~km}$ [1]. In 2013 these same statistics were $271 \mathrm{MW}$ and $29 \mathrm{~km}$ respectively [2]. With a cumulative European offshore wind capacity expected to reach $25 \mathrm{GW}$ by 2020 [1], the trend of larger OWPP further from shore is likely to continue making it essential to fully understand the applicability of the available transmission options.

As OWPP increase in size and move further from shore the economic technology for connection to shore changes. For small OWPP less than about $15 \mathrm{~km}$ from shore, Medium Voltage (MV) within the collection grid can be connected directly, avoiding the need for a costly Offshore Substation (OSS) [3]. As the transmission distance or power increases, transmission losses become unacceptably high and an OSS with an MV to High Voltage (HV) transformer is required. Underwater HVAC cables, however, suffer from high capacitance and therefore have a limited range [4]. Reactive compensation can increase the possible range but, eventually this investment exceeds that of using HVDC [5], [6]. Cost analyses of HVAC systems using compensation split between the OSS and shore have been studied extensively [7]-[10]. Another possibility to extend the range of HVAC is to include a intermediary compensation

This project has received funding from the European Union's Horizon 2020 research and innovation programme under the Marie Sklodowska-Curie grant agreement no. 765585 platform. In this regard the literature is found to be lacking. An additional proposal for extending the range of AC systems is Low Frequency Alternating Current (LFAC) [11]. A commonly proposed LFAC system operates at 1/3 standard frequency, extending HVAC transmission by reducing cable capacitance and skin effect [11]. Building on this idea, OFAC has been suggested [12]. The economic feasibility of LFAC and OFAC has only been studied to a limited extent and requires a more thorough investigation [11], [13], [14].

In this paper the authors have expanded upon a model originally developed in [7] to quantize the full economic range of HVAC for offshore wind transmission by including both intermediary compensation and OFAC transmission. To the best of the authors knowledge no economic comparison including both these technologies has been performed to date. In the following section a detailed description of the developed economic model is presented. Any assumed values are summarized in table IV of Appendix A. Results are presented following the description of the model.

\section{ECONOMIC MODEL}

\section{A. Wind Power Characteristics}

The wind profile described in [7] with wind frequency distribution of the annual time series shown in Fig. 1 is used. A diversified profile is assumed to be more suitable for OWPP spread out over a geographical large area. A diversified input profile produces fewer variations in output and spends less time at the generating extremes of zero and $100 \%$. The profile has a load factor of $40 \%$ and a load loss factor $(\delta)$ of $23 \%$.

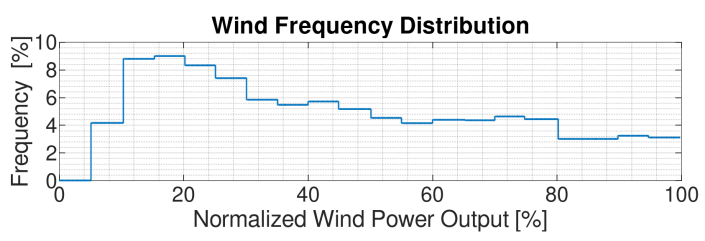

Fig. 1. Wind Frequency Distributions

\section{B. Cost Breakdown Methodology}

The cost model is based on work by [7] using empirical data from commercial projects. The method breaks down the OWPP cost into component calculations of Capital Expenditures (CAPEXs) and Operating Expenditures (OPEXs). 
CAPEX and OPEX are further divided into Terminal Costs (TCs) and Route Costs (RCs) as per fig. 2. TCs are distance independent quantities like a substation while RCs increase with distance from shore, the transmission cable is an example.

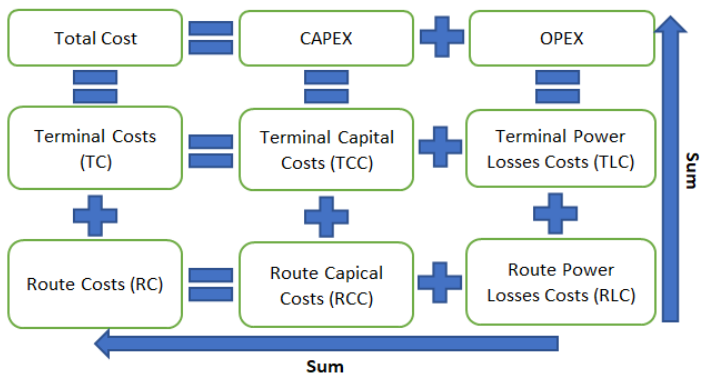

Fig. 2. Breakdown Of System Cost Model.

\section{C. $50 \mathrm{~Hz}, \mathrm{HVAC}$}

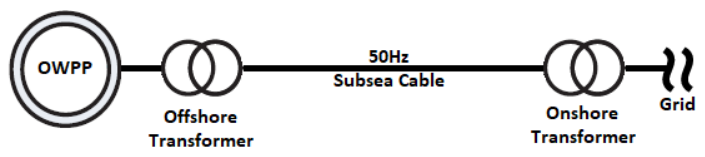

Fig. 3. Single line diagrams of HVAC transmission system.

1) Terminal Capital Cost (TCC): Fig. 3 shows the single line diagram of the modeled HVAC transmission system. The TCC of an HVAC connected OWPP can be approximated by the sum of the Offshore Power plant and Platform Cost (OPPC) and the Onshore Plant Cost (OPC) (1). The OPPC is the sum of a fixed cost $(F C)$ representing the foundation, float out and erection costs and a variable cost linearly dependent on the OWPP $\left(S_{T}\right)$ rating [7]. Here, $n_{T}$ and $S_{S T}$ are the number and size of the transformers. $f_{C T}$ and $p_{C T}$ are the variable platform and plant costs respectively. $d c$ is a cost factor for more than 1 transformer. The OPC is calculated using (3), developed for large transformers [15].

$$
\begin{aligned}
& T C C=O P P C+O P C \\
& O P P C_{h v a c}=F C_{h v a c}+\left[1+d c \cdot\left(n_{T}-2\right)\right] \\
& \cdot\left(f c_{T}+p c_{T}\right) \cdot n_{T} \cdot S_{S T} \\
& O P C_{\text {hvac }}=0.03327 \cdot S_{T}^{0.7513}
\end{aligned}
$$

2) Route Capital Cost (RCC): The RCCs can be approximated by the sum of the Compensation Cost (QC) and the Cable Cost (CBC) (4). QC (5) is the sum of the offshore $\left(Q_{o f f}\right)$ and onshore $\left(Q_{o n}\right)$ compensation multiplied by their respective costs: $\left(Q_{C o f f}\right)$ and $\left(Q_{C o n}\right)$ [7]. (6) gives the total amount of compensation $(\mathrm{Q})$ required to reach unity power factor $(p f)$ as a function of frequency $\left(f_{n}\right)$, cable capacitance $\left(C_{q c}\right)$, length $\left(l_{c}\right)$ and number of parallel cables $\left(n_{c}\right)$ [13]. The cost per unit length $\left(c_{c b l}\right)$ is found in [7]. Assuming a 50-50 split of onshore to offshore compensation the new line capacity $\left(P_{C}\right)$ is then defined by $(8)$ [13].

$$
\begin{gathered}
R C C=Q C+C B C \\
Q C=Q c_{o f f} \cdot Q_{o f f}+Q c_{o n} \cdot Q_{o n} \\
Q=V_{n}^{2} \cdot 2 \pi f_{n} C_{q c} \cdot l_{c} \cdot n_{c} \\
C B C=n_{c} \cdot c_{c b l} \cdot l_{c} \\
P_{C}=\sqrt{S_{c b l}^{2}-Q_{o n}^{2}}
\end{gathered}
$$

3) Terminal power Losses Cost (TLC): (9-11) define the offshore $\left(T L C_{o f f t}\right)$ and onshore $\left(T L C_{o n t}\right)$ transformer losses. TLC is a cumulative function taken over the lifetime $\left(T_{o p}\right)$ of the OWPP [13]. Here, $E_{o p}$ is the cost of energy, $V_{n}$ is nominal voltage, $\eta$ is efficiency of a transformer, $r_{c}$ the per unit resistance of the cable and $\delta$ is the load loss factor introduced in section II-A.

$$
\begin{gathered}
T L C=T L C_{o f f t}+T L C_{o n t} \\
T L C_{o f f t}=S_{T} \cdot p f \cdot\left(1-\eta_{o f f t}\right) \cdot T_{o p} \cdot \delta \cdot E_{o p} \\
T L C_{o n t}=\left[S_{T} \cdot p f-\left(\frac{S_{T} \cdot p f \cdot \eta_{o f f t}}{n_{c} \cdot V_{n}}\right)^{2}\right. \\
\left.\cdot r_{c} \cdot l_{c} \cdot n_{c}\right] \cdot\left(1-\eta_{o n t}\right) \cdot T_{o p} \cdot \delta \cdot E_{o p}
\end{gathered}
$$

4) Route power Losses Cost (RLC): are the costs associated with $I^{2} R$ losses of the transmission cable. Like the TLC, the RLC is cumulative over the lifetime of the OWPP. The RLC is defined as

$$
R L C_{h v a c}=\left(\frac{S_{T} \cdot p f \cdot \eta_{o f f t}}{n_{c} \cdot V_{n}}\right)^{2} \cdot r_{c} \cdot l_{c} \cdot n_{c} \cdot T_{o p} \cdot \delta \cdot E_{o p}
$$

\section{D. $H V D C$}

1) TCC: TCCs of an HVDC connected OWPP is calculated similarly to HVAC as the sum of OPPC and OPC (1). Converters are assumed to be of type Voltage Source Converter (VSC) with variable cost $c_{c o n}$. Cost data from [16] is used to estimate OPC (14).

$$
\begin{gathered}
O P P C_{h v d c}=F C_{h v d c}+\left[1+d c \cdot\left(n_{T}-2\right)\right] \\
\cdot c_{c o n} \cdot n_{c o n} \cdot S_{c o n} \\
O P C_{h v d c}=0.113 \cdot S_{T}
\end{gathered}
$$

2) RCC: As HVDC cables are not subject to reactive power flow due to cable capacitance [17], RCC is composed simply of $(\mathrm{CBC})$ given by (7).

3) TLC: (9-11) with appropriate efficiencies substituted and $p f=1$ are used for HVDC. The onshore inverter efficiency $\eta_{o n i}$ and the offshore rectifier efficiency $\eta_{o f f r}$ are substituted for the onshore and offshore transformer efficiencies; $\eta_{\text {ont }}$ and $\eta_{\text {offt }}$ respectively.

4) $R L C$ : is found by modifying (12) for a DC system to get (15). Here, $k$ is the cable loss factor and is set to 0.5 for HVDC cables according to [13].

$$
R L C_{h v d c}=2 \cdot\left(\frac{S_{T} \cdot \eta_{o f f r}}{n_{c} \cdot V_{n}}\right)^{2} \cdot r_{c} \cdot l_{c} \cdot n_{c} \cdot T_{o p} \cdot \delta \cdot E_{o p} \cdot k
$$


5) Cost Range of HVDC: A minimum and and maximum cost range for HVDC has been calculated (fig. 4 A,B). The minimum range assumes the entire transmission length is HVDC and no additional HVAC components are required. This would be the case if the wind farm collector grid were connected directly to the HVDC platform. The maximum estimate includes an HVAC collection platform including a transformer and $5 \mathrm{~km}$ of HVAC cable feeding into the HVDC converter station. Throughout this paper, unless explicitly stated the minimum estimate of HVDC is used for comparison.

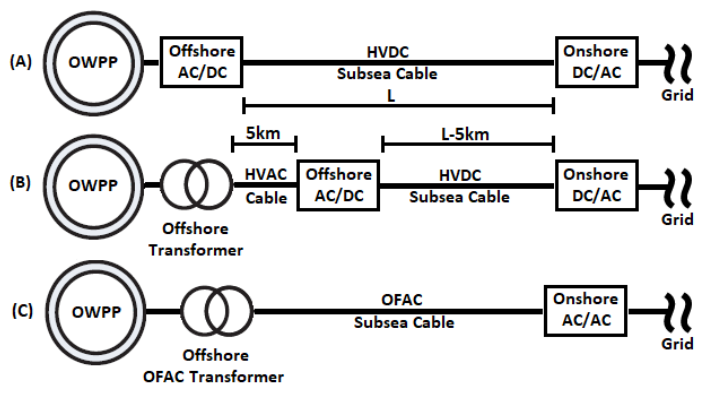

Fig. 4. Single line diagrams of (A) Minimum cost of HVDC. (B) Maximum cost HVDC. (C) OFAC

\section{E. OFAC}

1) TCC: The single line diagram of the modeled OFAC system is shown in fig. 4C. The TCC of an OFAC system is modeled similarly to a HVAC and HVDC given by (1). As no commercial OFAC OWPP projects exist, however, some further modeling assumptions are required.

The components most affected by a drop in frequency are transformers and reactors. Magnetic flux density does not change significantly with altering frequency, therefore to maintain the desired voltage, the number of turns or the area of the core or both must be changed an equal but opposite amount [18]. This effects the size and cost of the OSS. To account for this, cost factor $C f_{x f m}$ is added to (3) to obtain

$$
\begin{array}{r}
O P P C_{o f a c}=F C_{o f a c}+\left[1+d c \cdot\left(n_{T}-2\right)\right] \\
\cdot C f_{x f m} \cdot\left(f c_{T}+p c_{T}\right) \cdot n_{T} \cdot S_{S T}
\end{array}
$$

In order to size $C f_{x f m}$ we turn to studies estimating the increase in size required for $1 / 3$ frequency transformers. [18] showed that the overall increase in mass of the transformer could be limited to $77 \%$. [19] however, recommends that a minimum $100 \%$ increase be anticipated. To be conservative a factor of $100 \%$ is assumed. Extending this assumption for all frequencies, the relationship (17) was developed.

$$
C f_{x f m}=\left(\frac{50}{f_{\text {opt }}}+1\right) / 2, \quad f>0
$$

The OPC is primarily due to the AC/AC converter. According to [13], the number of active switches and reactive components for $\mathrm{AC} / \mathrm{AC}$ converters is greater than for $\mathrm{DC} / \mathrm{DC}$ therefore an $\mathrm{AC} / \mathrm{AC}$ converter station would at best be equal in cost to a Line Commutated Converter (LCC) HVDC station of similar size. Accordingly, the following relation developed by [20] for costing LCC is used:

$$
O P C_{o f a c}=0.08 \cdot S_{T}
$$

2) $R C C$ : RCC is modeled using (4) through (8). As above, (5) is modified for increased reactors size resulting in:

$$
Q C=C f_{x f m} \cdot Q c_{o f f} \cdot Q_{o f f}+Q c_{o n} \cdot Q_{o n} .
$$

3) TLC: (9) through (12) with appropriate efficiency substitutions are used for OFAC. The offshore transformer efficiency is assumed to be the same as HVAC, but onshore converter efficiency $\eta_{a c a c}$ is substituted in place of $\eta_{\text {ont }}$.

\section{F. Reliability}

In addition to costs described above, system reliability is considered in terms of of Corrective Maintenance (CM) and EENS. Total cost, including reliability is given by

$$
C O S T_{w r}=C A P E X+O P E X+C M+E E N S .
$$

1) $C M$ : is considered post fault, meaning it is the cost of replacement or repair of faulty equipment. Preventative maintenance is not considered within the scope. CM is calculated from the Mean Time To Repairs (MTTRs), Failure Rates (FRs) and Mean Cost per Repairs (MCs) summarized in table I and is given by (21).

TABLE I

RELIABILITy PARAMETERs [7]

\begin{tabular}{llll}
\hline Equipment & FR $[1 / y r]$ & MTTR $[$ months $]$ & $M C[M €]$ \\
\hline Transformers & 0.03 & 2(PCC) / 6(OSS) & 2.75 \\
Converters & 0.12 & 1 & 0.56 \\
Cables & $0.08 / 100 \mathrm{~km}$ & 2 & 0.56 \\
\hline
\end{tabular}

$$
\begin{array}{r}
C M=\left[\frac{n_{t} \cdot M C_{t}}{\frac{1}{F R_{t}}+\frac{M T T R_{t}}{T}}+\frac{n_{c} \cdot M C_{c}}{\frac{1}{F R_{c}}+\frac{M T T R_{c}}{T}}\right. \\
\left.+\frac{n_{d c} \cdot M C_{d c}}{\frac{1}{F R_{d c}}+\frac{M T T R_{d c}}{T}}\right] \cdot C F
\end{array}
$$

2) EENS: EENS is energy which must be curtailed in order to not exceed system capacity or load demand. A system capacity limit may be reached due to intentional under sizing of equipment or due to component failure. The calculation of EENS is as follows: If the per unit constrained capacity of system configuration $i$; $S_{c o n s, i}$, has a probability of occurring, $P_{\text {cons }, i}$, then $\mathrm{EENS}_{i}$ is given by

$$
E E N S_{i}=A_{c o n s, i} \cdot P_{c o n s, i} \cdot S_{p c c} .
$$

Where $A_{c o n s, i}$ is the area under the input profile curve and above the line $\mathrm{y}=S_{\text {cons }, i}$ of fig 5 . The EENS of the entire system is then the sum of all EENS ${ }_{i}$ over $n$ possible network configurations. A Capacity Outage Probability Table (COPT) is used when calculating the capacities and probabilities of the $n$ network configurations and is constructed as follows. 


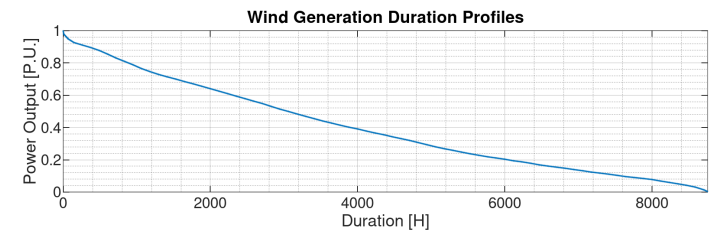

Fig. 5. Wind Duration Profiles

3) COPT: The creation of a COPT is illustrated by the following example. If a binary state piece of equipment $i$ has capacity; $\mathrm{C}_{i}, \mathrm{MTTR}_{i}$ and $\mathrm{FR}_{i}$, then the availability of the system, $\mathrm{A}_{i}$, is given by:

$$
A_{i}=\frac{1}{1+F R_{i} \cdot \frac{M T T R_{i} \cdot 30 \cdot 24}{8760}},
$$

and the $\mathrm{COPT}_{i}$ is constructed as shown in table II. The overall system COPT is achieved through the convolution of all individual COPTs by applying equations (24-25) for series and shunt components. Finally, rows with common capacities are combined through the summation of probabilities.

TABLE II

EXAMPLE COPT

\begin{tabular}{lll}
\hline State & Capacity $\left(\mathrm{S}_{\text {cons }, i}\right)$ & Probability $\left(\mathrm{P}_{\text {cons }, i}\right)$ \\
\hline 1 & $\mathrm{C}_{i}$ & $\mathrm{~A}_{i}$ \\
0 & 0 & $1-\mathrm{A}_{i}$ \\
\hline
\end{tabular}

$$
\begin{gathered}
C_{k}=: \begin{array}{ll}
C_{i}+C_{j} & \text { Series } \\
\min \left(C_{i}, C_{j}\right) & \text { Parallel }
\end{array} \\
P_{k}=P_{i} \cdot P_{j}
\end{gathered}
$$

\section{G. Equipment Sizing}

The cable characteristics and cost data of cables for HVAC and HVDC systems are those suggested in [7]. Due to reduced skin effect, the capacity of OFAC cables can not be obtained directly from data sheets. Therefore, cable capacity calculations are done according to IEC standard 60287 [21] with data sourced from [22]. Cost of OFAC cable is assumed to be the same as an equivalently sized $50 \mathrm{~Hz}$ cable. $50 \mathrm{~Hz}$ transformer sizes are restricted to $160 \mathrm{MVA}, 250 \mathrm{MVA}, 315 \mathrm{MVA}$, $500 \mathrm{MVA}, 630 \mathrm{MVA}$ and $800 \mathrm{MVA}$ while a continuum of sizes up to $2 \mathrm{GW}$ is assumed available for HVDC converters.

\section{H. Intermediate Platform}

The effect of an intermediary compensation platform has been investigated. The single line diagram of such a system is shown in fig 6. The foundation, float out and erection costs irrelevant of OWPP rating are modeled as a fixed cost of $10 \mathrm{M} €$. This value corresponds to the low end cost for a OSS recommended in [9]. The transmission cable is then split in two and compensation placed on the main OSS, the intermediate platform and onshore. The optimal distance from shore for the compensation platform is found by iterating through the entire distance to shore at $5 \mathrm{~km}$ spacings.

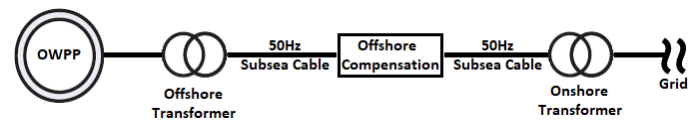

Fig. 6. Single line diagram of HVAC transmission system with intermediary compensation platform

\section{RESULTS}

\section{A. OFAC}

Examining fig. 7 it is apparent that gradually reducing the frequency creates a quasi linear cost function over the entire range while the cost of $50 \mathrm{~Hz} \mathrm{HVAC}$ becomes exponential after about $150 \mathrm{~km}$. At $600 \mathrm{MW}$, a $53 \mathrm{~km}$ wide cost effective window is created between $81 \mathrm{~km}$ and $134 \mathrm{~km}$. There is obvious improvement over the $16.7 \mathrm{~Hz}$ LFAC which is economic only between $96 \mathrm{~km}$ and $110 \mathrm{~km}$. This result is supported by the bottom of fig. 7 where it can be seen that a frequency of $16.7 \mathrm{~Hz}$ is rarely optimal, best only between $280 \mathrm{~km}$ and $300 \mathrm{~km}$. As the capacity of the OWPP increases the viable range shrinks. An analysis up to $1.5 \mathrm{GW}$ showed that beyond 800 MW OFAC has negligible applicability. Work by [13] on 16.7 Hz LFAC supports this conclusion.

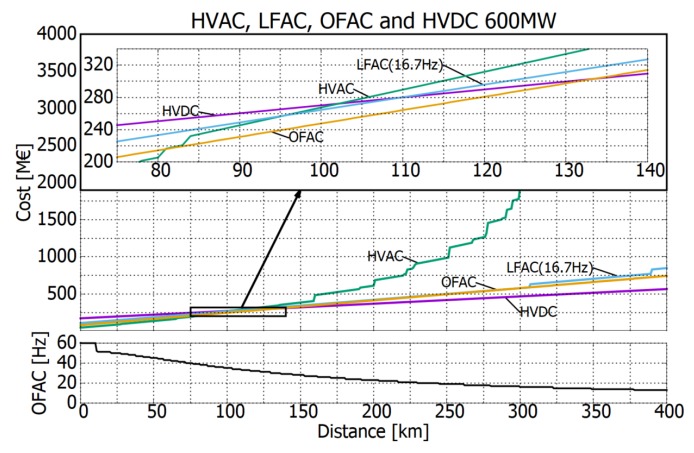

Fig. 7. $600 \mathrm{MW}$ HVAC, HVDC, OFAC cost comparison.

\section{B. Cable Selection}

An undersized HVAC export cable can be economic. This is due to the limited step sizes of HVAC cable and is best understood by examining in detail several HVAC transmission options. Table III summarizes the cost breakdown of 5 options for an 800 MW OWPP, located $90 \mathrm{~km}$ offshore. Option 1 uses $2-1000 \mathrm{~mm}^{2}$ export cables with a total capacity of $678 \mathrm{MW}$, significantly less than the $800 \mathrm{MW}$ OWPP capacity. Still, the lifetime cost of this configuration is less than that of upgrading to $3-500 \mathrm{~mm}^{2}$ cables as in option 2. High EENS in option 1 results from power curtailment above $678 \mathrm{MW}$. However, both lower RLC and RCC more than compensate. Option 3, increases capacity through increased system voltage. A drop in EENS is visible as well as a reduction in RLC. But these savings cannot be justified as the extra cost of RCC results in a net increase. 
TABLE III

COMPARATIVE COST BREAKDOWN OF $800 \mathrm{MW}$ HVAC TRANSMISSION OPTIONS AT $90 \mathrm{KM}$.

\begin{tabular}{|c|c|c|c|c|c|c|}
\hline $\begin{array}{c}\text { Voltage } \\
\text { (transformer) }\end{array}$ & $\begin{array}{c}\text { Cable } \\
\text { (Capacity) }\end{array}$ & $\begin{array}{l}\text { Total } \\
\text { Cost } \\
{[\mathrm{M} €]}\end{array}$ & $\begin{array}{l}\text { OPPC } \\
(\mathrm{OPC}) \\
{[\mathrm{M} €]}\end{array}$ & $\begin{array}{l}\text { RCC } \\
(\mathrm{QC}) \\
{[\mathrm{M} €]}\end{array}$ & $\begin{array}{c}\text { RLC } \\
\text { (TLC) } \\
{[\mathrm{M} €]}\end{array}$ & $\begin{array}{l}\text { EENS } \\
(\mathrm{CM}) \\
{[\mathrm{M} €]}\end{array}$ \\
\hline $\begin{array}{c}220 \mathrm{kV} \\
(2-500 \mathrm{MW})\end{array}$ & $\begin{array}{c}2-1000 \mathrm{~mm}^{2} \\
(678 \mathrm{MW})\end{array}$ & 339.4 & $\begin{array}{l}56 \\
(4)\end{array}$ & $\begin{array}{c}180 \\
(10.9)\end{array}$ & $\begin{array}{c}27 \\
(16.1)\end{array}$ & $\begin{array}{l}41.7 \\
(3.7)\end{array}$ \\
\hline $\begin{array}{c}220 \mathrm{kV} \\
(2-500 \mathrm{MW})\end{array}$ & $\begin{array}{l}3-500 \mathrm{~mm}^{2} \\
(789 \mathrm{MW})\end{array}$ & 357.2 & $\begin{array}{l}56 \\
(4)\end{array}$ & $\begin{array}{c}220 \\
(12.5)\end{array}$ & $\begin{array}{c}32.6 \\
(16.1)\end{array}$ & $\begin{array}{l}12.1 \\
(3.9)\end{array}$ \\
\hline $\begin{array}{c}400 \mathrm{kV} \\
(2-500 \mathrm{MW})\end{array}$ & $\begin{array}{l}2-800 \mathrm{~mm}^{2} \\
(1052 \mathrm{MW})\end{array}$ & 378.8 & $\begin{array}{l}56 \\
(4)\end{array}$ & $\begin{array}{l}252 \\
(26)\end{array}$ & $\begin{array}{c}9.5 \\
(16.2)\end{array}$ & $\begin{array}{l}12.1 \\
(3.9)\end{array}$ \\
\hline $\begin{array}{c}220 \mathrm{kV} \\
(1-800 \mathrm{MW})\end{array}$ & $\begin{array}{c}2-1000 \mathrm{~mm}^{2} \\
(678 \mathrm{MW})\end{array}$ & 356.2 & $\begin{array}{c}37.9 \\
(4)\end{array}$ & $\begin{array}{c}180 \\
(10.9)\end{array}$ & $\begin{array}{c}27 \\
(16.1)\end{array}$ & $\begin{array}{l}78.4 \\
(2)\end{array}$ \\
\hline $\begin{array}{c}* 220 \mathrm{kV} \\
(2-500 \mathrm{MW})\end{array}$ & $\begin{array}{c}2-1000 \mathrm{~mm}^{2} \\
(708 \mathrm{MW})\end{array}$ & 337 & $\begin{array}{l}66 \\
(4)\end{array}$ & $\begin{array}{c}180 \\
(12.2)\end{array}$ & $\begin{array}{c}27.1 \\
(16.2)\end{array}$ & $\begin{array}{l}27.7 \\
(3.7)\end{array}$ \\
\hline
\end{tabular}

\section{Transformer Selection}

Transformers should be sized based on cable capacity not on system capacity. This may result in undersized transformers. The extra investment required for at least 2 parallel transformers is justified by the gain in reliability. Comparing options 1 and 4 of table III the effect on system cost is apparent. Using a single $800 \mathrm{MW}$ transformer reduces OPPC but this is more than offset by a rise in EENS. The conclusions related to cable and transformer size are supported by work performed in [7].

\section{Intermediate Compensation Platform}

The use of a compensation platform can be beneficial. Fig. 8 summarizes the cost effective regions of each technology. The upper and lower estimates for HVDC are included creating a boundary region where only the lower bound of HVDC is economic (grey). The true boundary between HVAC and HVDC systems likely lies somewhere inside this region. It is clear that a compensation platform can increase the economic range of HVAC (red). The comparison of component costs shown in fig. 9 demonstrates how an intermediate compensation platform linearizes the HVAC cost function. The economic range created by linearization is shown in the top of fig. 10. On the bottom of fig. 10 the optimal position of the compensation platform is displayed. The cost difference between onshore and offshore compensation pushes the mean optimal placement of the platform slightly past halfway out to sea.

A compensation platform is of benefit in 2 ways. First is when export cable size can be reduced. This situation can be seen in fig. 11 . At $1250 \mathrm{MW}$ and $130 \mathrm{~km}$ the savings are dramatic. The compensation platform allows for the use of $2-400 \mathrm{kV}$ $800 \mathrm{~mm}^{2}$ cables instead of $4-220 \mathrm{kV}-630 \mathrm{~mm}^{2}$ cables. This results in a savings of over $100 \mathrm{M} €$. Second, by comparing the first and final option for transmission at $800 \mathrm{MW}$ in table III a more subtle benefit is observable. Note that the cable size is $2-220 \mathrm{kV}-10000 \mathrm{~mm}^{2}$ for both options yet option 5 is more economic. This occurs as the compensation platform increases the export capacity of the cable resulting in a reduction of EENS. The savings in EENS more than compensate for the extra cost of the platform construction and extra compensation.

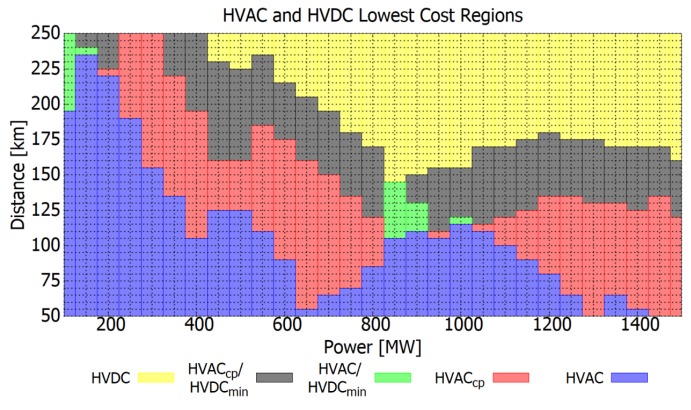

Fig. 8. Low Cost Regions of HVAC and HVDC systems.

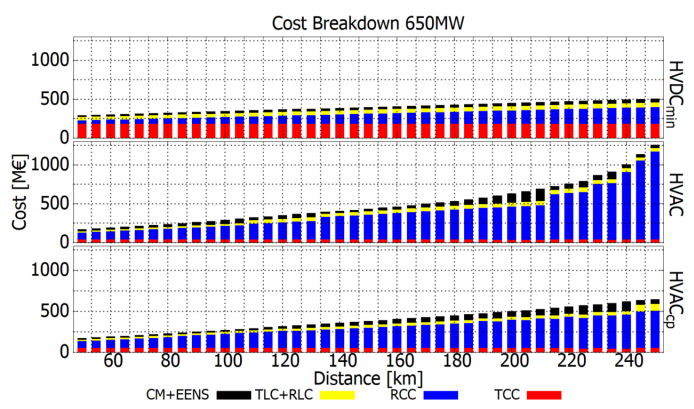

Fig. 9. Cost Breakdown at $650 \mathrm{MW}$.

\section{E. Offshore Grid Expansion}

A possible advantage of using compensation platforms is the ability to gradually expand the offshore grid in an optimal manner without excessive up front cost as would be required with an HVDC connection. Fig. 11 demonstrates a possible expansion scenario. At $600 \mathrm{MW}$ and $130 \mathrm{~km}$ the cheapest option uses $1-400 \mathrm{kV} 800 \mathrm{~mm}^{2}$ cable with compensation $65 \mathrm{~km}$ from shore. To increase the capacity to $1250 \mathrm{MW}$ an additional $400 \mathrm{kV} 800 \mathrm{~mm}^{2}$ cable can be added in parallel. Expanding the offshore grid in this manner limits the risk of investing in infrastructure based on projected future expansion while still achieving a system with the lowest cost per watt.

A further possibility for cost reduction may exist if existing Offshore structures can be converted to act in addition as compensation platforms. For example, existing OSSs off the coast of Belgium, including Elia's Modular Offshore Grid

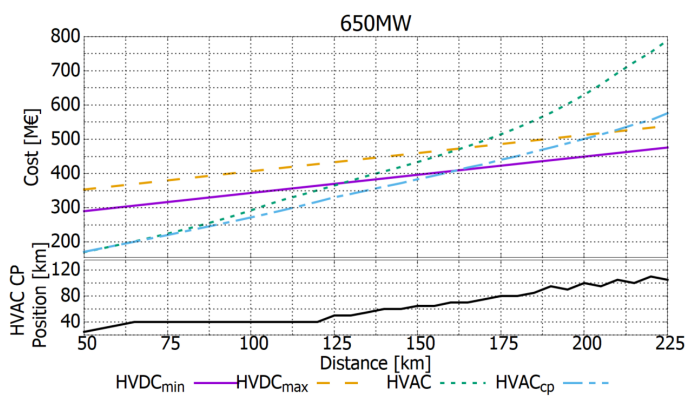

Fig. 10. Crossing points of cost functions at $650 \mathrm{MW}$ (Top). Position of compensation platform for (Bottom). 
(MOG), range from about $30 \mathrm{~km}$ to $60 \mathrm{~km}$ out to sea [23], ideally located to act as "stepping stones" to reach wind resources further offshore.

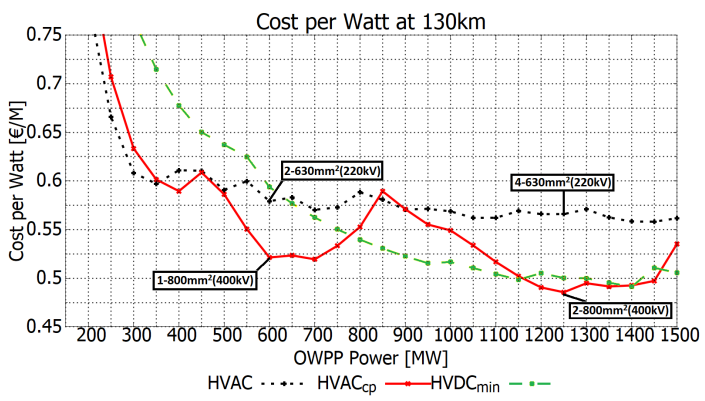

Fig. 11. Cost per watt at $130 \mathrm{~km}$ offshore.

\section{Conclusions}

An economic comparison of HVAC options including OFAC and mid point compensation has been compared to HVDC transmission. A range of viable economic regions for each technology has been estimated. The study of OFAC produced a small viable economic window at medium power levels, however, this viable region disappeared as power levels increased. A mid point compensation platform was found to have a large range of applicability. A compensation platform was shown to be useful when the export cable size can be reduced and in the situation where cable size remains constant but increased capacity reduces EENS. Additionally the study found that a reduction in the HVAC export cable is often economic. Furthermore, the increased reliability of two partially sized transformers versus one full sized was found to always be worth while. Further investigation into the optimal undersizing of cables and transformers is needed as well as an investigation into what effects this may have on equipment life expectancy.

\section{APPENDIX A}

TABLE IV

MODELING ASSUMPTIONS

\begin{tabular}{llr}
\hline \multicolumn{1}{c}{ Variable } & \multicolumn{1}{c}{ Definition } & \multicolumn{1}{c}{$\begin{array}{c}\text { Assumed } \\
\text { Value }\end{array}$} \\
\hline$F C_{\text {hvac }}$ & Fixed cost of HVAC transformer platform & $5.6 \mathrm{M} €$ \\
$F C_{h v d c}$ & Fixed cost of offshore HVDC platform & $28 \mathrm{M} €$ \\
$F C_{o f a c}$ & Fixed cost of offshore OFAC station platform & $5.6 \mathrm{M} €$ \\
$f c_{T}$ & Variable cost of HVAC transformer platform & $0.0224 € / \mathrm{VA}$ \\
$p c_{T}$ & Variable Cost of HVAC offshore plant cost & $0.028 € / \mathrm{VA}$ \\
$c_{\text {con }}$ & Variable cost of offshore HVDC converter & $0.123 € / \mathrm{VA}$ \\
$Q c_{o f f}$ & Unit cost of offshore compensation & $0.028 €$ \\
$Q c_{o n}$ & Unit cost of onshore compensation & $0.0168 € / \mathrm{VAR}$ \\
$E_{o p}$ & Cost of energy & $56 € / \mathrm{MWh}$ \\
$T_{o p}$ & Total operational hours & $365 \times 24 \times 15 \mathrm{hrs}$ \\
$\delta$ & Load Loss Factor & $23 \%$ \\
$d c$ & Cost factor for >1 OSS transformer or converter & 0.2 \\
$p f$ & Power factor & 1 \\
$\mathrm{CF}$ & Capitalization Factor & 10 \\
$\eta_{\text {offt }}, \eta_{\text {ont }}$ Efficiency of the offshore/onshore transformer & $99.4 \%$ \\
$\eta_{\text {oni }}$ & Efficiency of the onshore inverter station & $98.19 \%$ \\
$\eta_{o f f r}$ & Efficiency of the offshore rectifier station & $98.28 \%$ \\
$\eta_{a c a c}$ & Onshore AC/AC converter efficiency & $99.12 \%$ \\
\hline
\end{tabular}

\section{REFERENCES}

[1] Ariola Mbistrova WindEurope Business Intelligence Tom Remy. Key trends and statistics 2017. In Offshore Wind in Europe, Feb 2018.

[2] Justin Wilkes Jerome Guillet Paul Wilczek Athanasia Arapogianni, Jacopo Moccia. key trends and statistics 2012. In Offshore Wind in Europe, Jan 2013.

[3] Josef Schachner. Power Connections for Offshore Wind Farms Diploma Thesis. PhD thesis, TU Delft, 2004.

[4] Tiago Antunes, Tiago Alexandre dos Reis Antunes, Paulo Jorge da Costa Santos, and Armando José Pinheiro Marques Pires. Limitations of HVAC Offshore Cables in Large Scale Offshore Wind Farm Applications. Technical report.

[5] M Pavlovsky and P Bauer. Cable Selection and Shunt Compensation for Offshore Windparks. Technical report.

[6] Hakan Ergun, D. Van Hertem, and R. Belmans. Transmission system topology optimization for large-scale offshore wind integration. Sustainable Energy, IEEE Transactions on, 3(4):908-917, 2012.

[7] Predrag Djapic and Goran Strbac. Centre for Sustainable Electricity and Distributed Generation Cost Benefit Methodology for Optimal Design of Offshore Transmission Systems. Technical report, 2008.

[8] DTI Department of Trade and Industry contractor ODE Limited. Study of the costs of offshore wind generation. Technical report, 2007.

[9] M. Dicorato, G. Forte, M. Pisani, and M. Trovato. Guidelines for assessment of investment cost for offshore wind generation. Renewable Energy, 2011.

[10] Hakan Ergun, Dirk Van Hertem, and Ronnie Belmans. Cost of wind. pages 753-758. Betancourt, U, ENERGYNAUTICS GMBH, 2010.

[11] Jonathan Ruddy, Ronan Meere, and Terence Odonnell. A comparison of vsc-hvdc with low frequency ac for offshore wind farm design and interconnection. Energy Procedia, 80(C):185-192, 2015.

[12] Uttam S Satpute and D R Joshi. Optimum Frequency-based Design of Off-shore Wind Power Plant (OWPP). In IEEE PES Asia-Pacific Power and Energy Engineering Conference (APPEEC), 2017.

[13] X Xiang, M M C Merlin, and T C Green. Cost Analysis and Comparison of HVAC, LFAC and HVDC for Offshore Wind Power Connection. In The 12th IET International Conference on AC and DC, 2016.

[14] Jos Luis Domnguez-Garca, Daniel J. Rogers, Carlos E. Ugalde-Loo, Jun Liang, and Oriol Gomis-Bellmunt. Effect of non-standard operating frequencies on the economic cost of offshore ac networks. Renewable Energy, 44:267-280, 2012.

[15] Lazaros P Lazaridis. Economic Comparison of HVAC and HVDC Solutions for Large Offshore Wind Farms under Special Consideration of Reliability. PhD thesis, Royal Institute of Technology Department of Electrical Engineering, 2005.

[16] ABB Power Technologies AB Power Systems DC. Middletown norwalk transmission project. technical description of vsc hvdc converter and cable technology. Technical report, October 204.

[17] Abb hvdc technical advantages. https://new.abb.com/systems/hvdc/whyhvdc/technical-advantages.

[18] P B Wyllie, Y Tang, L Ran, T Yang, and J Yu. Low Frequency AC Transmission - Elements of a Design for Wind Farm Connection. Technical report.

[19] W. Fischer, R. Braun, and I. Erlich. Low frequency high voltage offshore grid for transmission of renewable power. In 2012 3rd IEEE PES Innovative Smart Grid Technologies Europe (ISGT Europe), pages 16, Oct 2012

[20] S. Lundberg. Performance comparison of wind park configuration. technical report. Technical report, Chambers University of Technology, Goteborg, Sweden, 2003.

[21] International Electrotechnical Commission. International Standard IEC 60287-1-1, volume ISBN 2-8318-5992-1. November 2001.

[22] ABB High Voltage Cable Unit. Xlpe submarine cable systems. Technical report, January 2010

[23] 4c offshore renewable map. https://www.4coffshore.com/offshorewind/, 2018. 